\title{
PERENCANAAN DINDING PENAHAN TANAH CILEUNGSI - CIBEET KABUPATEN BOGOR KM 96 STA 96+900 - STA 97+020
}

\author{
${ }^{1}$ Yudi Sekaryadi, ${ }^{2}$ Ilham, ${ }^{3}$ Salsa Nadia Inayah Rahmadika \\ Program Studi Teknik Sipil Fakultas Teknik Universitas Suryakancana \\ yudisekaryadi65@gmail.com , ilhamipong@yahoo.com, sanaira09@gmail.com
}

\begin{abstract}
Abstrak
Kabupaten Bogor merupakan daerah yang mempunyai curah hujan tinggi, sehingga tidak luput dari bencana longsor yang dapat menyebabkan amblasnya jaringan jalan raya, Seperti yang terjadi pada ruas jalan Cileungsi - Cibeet STA 96+900 sampai dengan STA 97+020 yang mengalami kerusakan badan jalan akibat lereng yang mengalami longsor setelah beberapa hari turun hujan. Perencanaan dinding penahan tanah tipe kantilever ini bertujuan untuk meminimalisir terjadinya longsor kembali di ruas jalan tersebut. Dalam perencanaan dinding penahan tanah tipe kantilever ini mengacu pada SNI persyaratan perancangan geoteknik tahun 2017 dan untuk perencanaan tebal perkerasan lentur mengacu pada Perencanaan Tebal Perkerasan Lentur Jalan Raya Manual Desain 2017. Dari hasil perencanaan, dimensi dinding penahan tanah yang digunakan untuk titik 1 didapat nilai stabilitas guling 2.10, stabilitas geser 8,6 dan daya dukung tanah 12,838. Sedangkan dimensi dinding penahan tanah yang digunakan untuk titik 2 didapat nilai stabilitas guling 2.51, stabilitas geser 2.80 dan daya dukung tanah 4.8 .
\end{abstract}

Kata kunci : Dinding penahan tanah, tipe kantilever, Daya dukung tanah

\section{PENDAHULUAN}

Indonesia merupakan negara yang terletak pada iklim tropis. Iklim tropis sendiri mempunyai 2 musim yaitu musim hujan dan musim kemarau. Perubahan musim tersebut memberikan pengaruh penting terhadap fenomena alam. Pengaruh peristiwa alam yang berupa penguapan (evaporasi dan evapotranpirasi) dan persipitasi (hujan) tersebut mengakibatkan terjadinya fluktuasi muka air tanah. Naiknya muka air tanah akibat hujan mempengaruhi sifat dan perilaku tanah dalam merespon tekanan/beban yang terjadi. Akhir-akhir ini, sering terjadi bencana tanah longsor di Indonesia, yang dikaitkan dengan datangnya musim hujan.

Kabupaten Bogor memiliki luas wilayah sekitar $2.071,21 \mathrm{Km}^{2}$ terletak antara $6,19^{\circ} \mathrm{LU}-6,47^{\circ} \mathrm{LS}$ dan $106^{\circ} 1^{\prime}$ - $107^{\circ} 103^{\prime}$ BT, yang berdekatan dengan Ibukota Negara sebagai pusat pemerintahan, dengan aktivitas pembangunan yang cukup tinggi. Kabupaten Bogor terletak pada ketinggian berkisar antara $50-3000 \mathrm{mdpl}$ dengan topografi yang beragam dari landai hingga bukit terjal, hal ini mengakibatkan beberapa segmen ruas jalan harus berada pada lereng yang rawan terjadi longsor.

Selain relatif terletak di deretan pergunungan Kabupaten Bogor merupakan daerah yang mempunyai curah hujan tinggi, sehingga tidak luput dari bencana longsor yang dapat menyebabkan amblasnya jaringan jalan raya, seperti yang terjadi di ruas jalan Cileungsi -Cibeet STA 96+900 sampai dengan STA 97+020 yang mengalami kerusakan badan jalan akibat lereng yang mengalami longsor setelah beberapa hari turun hujan.

Peristiwa tanah longsor atau dikenal sebagai gerakan massa tanah, batuan atau kombinasi keduanya, sering terjadi pada lereng-lereng alam atau buatan, sebenarnya merupakan fenomena alam dimana alam mencari keseimbangan baru akibat adanya gangguan atau faktor yang mempengaruhi dan menyebabkan terjadinya pengurangan kuat geser serta peningkatan tegangan geser tanah.

Penulisan ini mengkaji perencanaan dinding penahan tanah yang dibangun untuk meminimalisir terjadinya longsor kembali dan juga perbaikan perkerasan jalan pada ruas jalan tersebut. Berdasarkan latar belakang diatas, maka dapat diuraikan beberapa rumusan masalah :

1. Berapakah dimensi perencanaan dinding penahan tanah, untuk ruas Jalan CileungsiCibeet KM 96 TA 96+900 - STA 97+020 Kabupaten Bogor? 
2. Apakah dimensi perencanaan dinding penahan tanah yang di desain aman terhadap Guling(Overturning), Geser (Slidding) dan Keruntuhan Daya Dukung?

\section{TINJAUAN PUSTAKA}

\section{a. Perencanaan Dimensi DPT}

Dalam merencanakan dinding penahan tanah, hal yang harus dilakukan adalah :

1. Mengasumsikan suatu dimensi.

2. Lakukan cek stabilitas yaitu guling, geser dan daya dukung terhadap dimensi yang direncanakan.

3. Jika sudah dilakukan cek stabilitas dan hasil dari dimensi tersebut tidak memnuhi syarat, maka perlu dilakukan desain dimensi awal kembali. Dimensi awal dinding penahan tanah menurut SNI 8460:2017 tentang persyaratan perancangan geoteknik adalah seperti gambar di bawah ini :

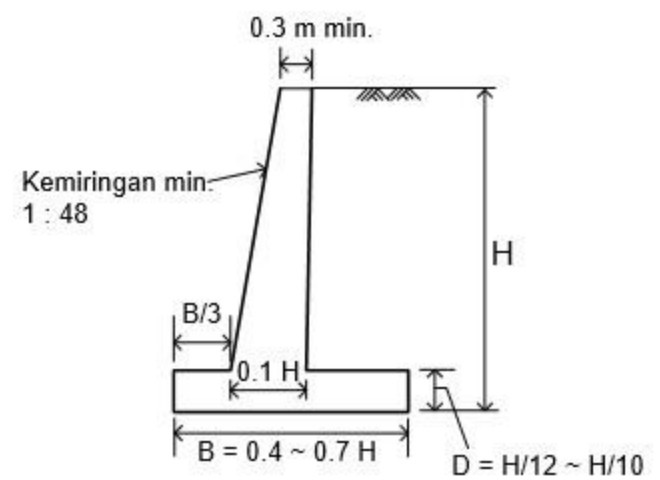

Gambar 1. Persyaratan dimensi awal dinding penahan tanah

Sumber : SNI Perencanaan Geoteknik (8460:2017)

\section{b. Tekanan tanah lateral}

1. Tekanan tanah lateral aktif

Menurut teori Rankine besarnya gaya lateral pada dinding akibat tekanan tanah aktif pada dinding setinggi $\mathrm{H}$ dapat dinyatakan dalam persamaan berikut :

$\mathrm{Pa}=1 / 2 \gamma \mathrm{Ka} \mathrm{H} 2$

Dengan harga Ka untuk tanah datar menurut Rankine :

$\mathrm{Ka}=$
$\operatorname{tg}^{2}\left(45-\frac{\phi}{2}\right)$

Dengan :

$\mathrm{Ka}=$ Koefisien aktif $\phi=$ Sudut geser tanah $\left(^{\circ}\right)$

$\mathrm{H}=$ tinggi dinding $(\mathrm{m})$

$\gamma=$ Berat isi tanah $(\mathrm{kN} / \mathrm{m} 3)$

2. Tekanan tanah lateral pasif

Menurut teori Rankine besarnya gaya lateral pada satuan lebar dinding akibat tekanan tanah pasif setinggi $\mathrm{H}$ dapat dinyatakan dalam persamaan berikut :

$\mathrm{Pp}=1 / 2 \gamma \mathrm{Kp} \mathrm{H}$

Dengan harga $\mathrm{Kp}$ untuk tanah datar menurut Rankine :

$\mathrm{Kp}=\operatorname{tg}^{2}\left(45+\frac{\Phi}{2}\right)$

Dengan :

$\mathrm{Kp}=$ Koefisien pasif

$\phi=$ Sudut geser tanah $\left(^{\circ}\right)$

$\mathrm{H}=$ tinggi dinding $(\mathrm{m})$

$\gamma=$ Berat isi tanah $\left(\mathrm{kN} / \mathrm{m}^{3}\right)$

\section{c. Stabilitas dinding penahan tanah}

1. Stabilitas terhadap guling (overturning)

Faktor aman akibat terhadap penggulingan (Fgl), didefinisikan sebagai : $\mathrm{Fgl}=\frac{\sum \mathrm{M}_{R}}{\sum \mathrm{M}_{O}}(2.5$

Dengan :

$\sum \mathrm{MR}=$ Jumlah momen dari gaya-gaya yang menahan guling $=\mathrm{W}$

$\sum \mathrm{MO}=$ Jumlah momen dari gaya-gaya yang menyebabkan guling

$\mathrm{W}=$ Berat tanah diatas pelat fondasi + berat sendiri dinding penahan $(\mathrm{kN})$.

$$
=\mathrm{P}_{\mathrm{h}}\left(\frac{\mathrm{H}^{\prime}}{3}\right)
$$

$\mathrm{W}=$ Berat tanah diatas pelat fondasi + berat sendiri dinding penahan $(\mathrm{kN})$

Momen yang menghasilkan guling :

$\mathrm{Mo}=\left(\mathrm{Pa}_{1} . \mathrm{H} / 2\right)+\left(\mathrm{Pa}_{2} . \mathrm{H} / 3\right)$

Momen yang menahan guling :

(prosedur perhitungan dapat dilakukan seperti pada tabel 1) 
Tabel 1 Prosedur perhitungan momen penahan guling

\begin{tabular}{|c|c|c|c|c|}
\hline $\begin{array}{l}\text { Komp } \\
\text { onen }\end{array}$ & $\begin{array}{c}\text { Luas } \\
\left(\mathrm{m}^{2}\right)\end{array}$ & $\mathrm{W}(\mathrm{kN})$ & $\begin{array}{c}\text { Jarak } \\
(\mathrm{m})\end{array}$ & $\begin{array}{c}\text { Momen } \\
(\mathrm{kNm})\end{array}$ \\
\hline 1 & $\mathrm{~A} 1$ & $\begin{array}{c}\mathrm{W} 1=\gamma_{\mathrm{a}} \mathrm{x} \\
\mathrm{A} 1\end{array}$ & $\mathrm{X} 1$ & $\begin{array}{c}\mathrm{M} 1=\mathrm{W} 1 \mathrm{x} \\
\mathrm{X} 1\end{array}$ \\
\hline 2 & A2 & $\begin{array}{c}\mathrm{W} 2=\gamma_{\mathrm{a}} \mathrm{x} \\
\mathrm{A} 2\end{array}$ & $\mathrm{X} 2$ & $\begin{array}{c}\mathrm{M} 1=\mathrm{W} 1 \mathrm{x} \\
\mathrm{X} 2\end{array}$ \\
\hline 3 & A3 & $\begin{array}{c}\mathrm{W} 3=\gamma_{\mathrm{a}} \mathrm{x} \\
\mathrm{A} 3\end{array}$ & X3 & $\begin{array}{c}\mathrm{M} 1=\mathrm{W} 1 \mathrm{x} \\
\mathrm{X} 3\end{array}$ \\
\hline 4 & A4 & $\begin{array}{c}\mathrm{W} 4=\gamma_{\mathrm{b}} \mathrm{x} \\
\mathrm{A} 4\end{array}$ & $\mathrm{X} 4$ & $\begin{array}{c}\mathrm{M} 1=\mathrm{W} 1 \mathrm{x} \\
\mathrm{X} 4\end{array}$ \\
\hline & & $\Sigma \mathrm{V}$ & & $\Sigma \mathrm{MR}$ \\
\hline
\end{tabular}

$\gamma_{\mathrm{a}}=$ Berat volume beton $\gamma_{\mathrm{a}}=$ Berat volume tanah

Nilai faktor keamanan untuk guling minimum adalah 2

2. Stabilitas terhadap geser (sliding)

Faktor keamanan terhadap stabilitas geser dapat dinyatakan dengan rumus:

$$
\mathrm{Fgs}=\frac{\sum \mathrm{R}_{h}}{\sum \mathrm{P}_{h}}
$$

Dengan $\sum \mathrm{Rh}$ didapat dengan menggunakan persamaan:

$\sum \mathrm{Rh}=\Sigma \mathrm{V} \cdot \tan \phi+\mathrm{B} \cdot \mathrm{c}+\mathrm{Pp}$

Dengan :

$\sum \mathrm{Rh}=$ Tahanan DPT terhadap penggeseran $\Sigma \mathrm{Ph}=$ Gaya yang mendorong $(\mathrm{kN}) \mathrm{c}=$ Kohesi tanah dasar $(\mathrm{kN} / \mathrm{m} 2)$

$\mathrm{B}=$ Lebar fondasi $(\mathrm{m})$

Menurut SNI 8460:2017 Faktor aman terhadap penggeseran dasar fondasi (Fgs) minimum, diambil 1,5 .

3. Stabilitas terhadap daya dukung tanah

Faktor keamanan terhadap stabilitas daya dukung tanah dapat dinyatakan dengan rumus:

$\mathrm{F}=\frac{q u}{q}$

Kapasitas dukung ultimit dengan menggunakan persamaan Meyerhof (1963):

$q u=c 2 . N c$. Fcd. Fci $+q \cdot$ Nq. Fqd . Fqi $+\frac{1}{2} \gamma_{2}$

. B'. N $\gamma$. F $\gamma \mathrm{d}$. F $\gamma \mathrm{i}$.

Dengan,

$$
\begin{array}{ll}
\mathrm{q} & =\gamma_{2} \times \mathrm{D} \\
& =\mathrm{D}=\text { kedalaman DPT } \\
\text { Fcd, Fqd, F } \gamma \mathrm{d} & =\text { faktor kedalaman } \\
\text { Fci, Fqi, } \mathrm{F}_{\gamma \mathrm{i}} & =\text { faktor inklinasi } \\
\mathrm{Nc}, \mathrm{Nq}, \mathrm{N} \gamma & =\text { faktor-faktor kapasitas dukung }
\end{array}
$$

$$
\begin{aligned}
& \text { B' = lebar efektif pondasi (m) } \\
& \mathrm{e}=\text { eksentrisitas beban }(\mathrm{m}) \\
& \gamma \quad=\text { berat volume tanah }(\mathrm{kN} / \mathrm{m} 3)
\end{aligned}
$$

Nilai faktor aman terhadap keruntuhan kapasitas dukung menurut SNI 8640:2017 minimumnya sebesar 3 .

\section{METODOLOGI}

\section{a. Data Umum}

Obyek penelitian untuk penulisan ini adalah Perencanaan dinding penahan tanah di ruas jalan Cileungsi-Cibeet Kabupaten Bogor, dimulai dari STA awal 96+900 - STA 97+020, dengan panjang penanganan $120 \mathrm{~m}$.

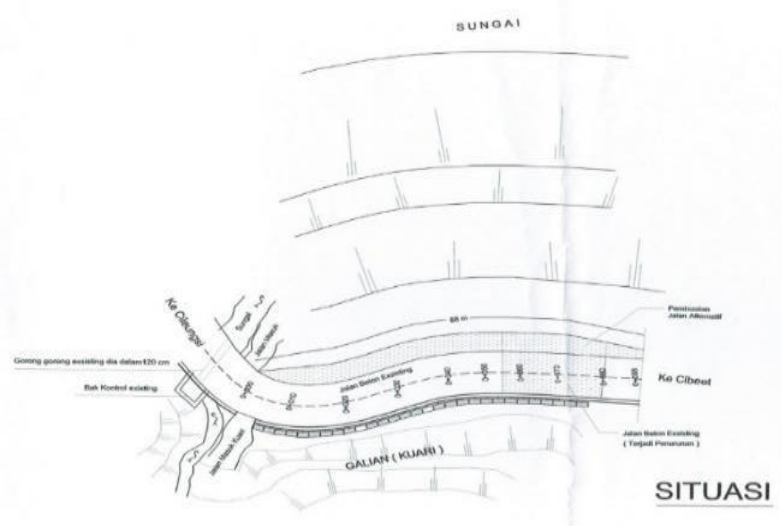

Gambar 2. Situasi Daerah Perencana Rehabilitasi Sumber: Dinas Bina Marga Provinsi Jawa Barat (2021)

\section{b. Data Sekunder}

Beberapa data sekunder yang didapatkan adalah: Studi literatur mempelajari kajian-kajian atau literatur yang berkaitan dengan perencanaan bangunan, di antaranya:
1. Data topografi
2. Data CBR tanah dasar
3. Data pengujian SPT

\section{PEMBAHASAN}

Untuk dapat memperhitungkan kestabilan dari dinding penahan tanah, diperlukan parameter paramater dari tanah yang akan direncanakan dinding penahan tanah.: 
Tabel 2. Data tanah pada lokasi

\begin{tabular}{ccc}
\hline Jenis & $\begin{array}{c}\text { Tanah } \\
\text { urugan }\end{array}$ & Tanah asli \\
\hline $\begin{array}{c}\text { Berat volume tanah } \\
(\gamma)\end{array}$ & $18,2 \mathrm{kN} / \mathrm{m}^{3}$ & $18,2 \mathrm{kN} / \mathrm{m}^{3}$ \\
\hline $\begin{array}{c}\text { Sudut gesek dalam } \\
(\phi)\end{array}$ & $31,35^{\circ}$ & $30,24^{\circ}$ \\
\hline Kohesi $(\mathrm{c})$ & 0 & $19,4 \mathrm{kN} / \mathrm{m} 2$ \\
\hline
\end{tabular}

Sumber : Dinas Bina Marga Prov. Jawa Barat (2020)

\section{1) DPT titik 1}

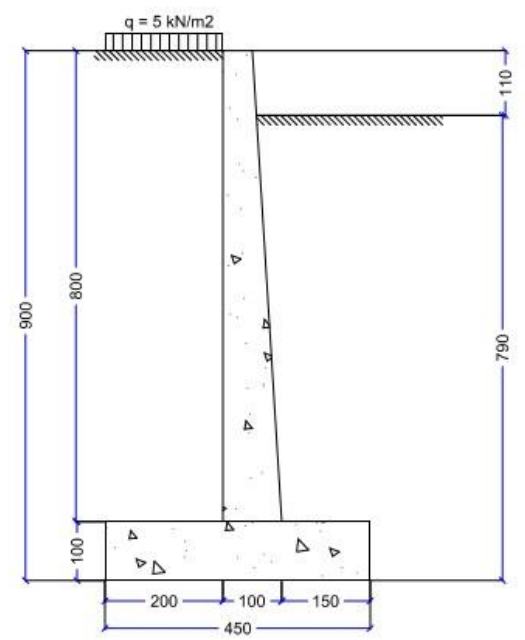

Gambar 3. Desain dinding penahan tanah titik

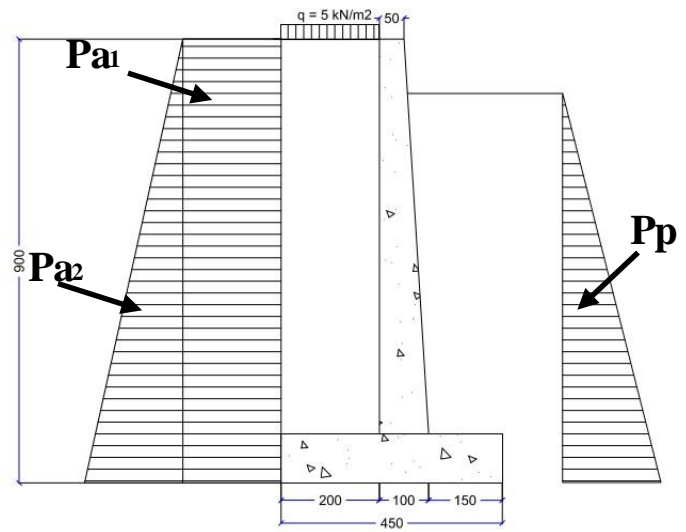

Gambar 4. Diagram tekanan tanah DPT titik1

a. Tekanan tanah aktif $(\mathrm{Pa})$

- Koefisien tekanan tanah aktif (Ka)

$$
\begin{aligned}
& =\operatorname{tg}^{2}\left(45-\frac{\phi}{2}\right) \\
\mathrm{Ka} & =\operatorname{tg}^{2}\left(45-\frac{31,35}{2}\right)
\end{aligned}
$$

$$
\begin{aligned}
& =\operatorname{tg}^{2}(29,325) \\
& =0,315
\end{aligned}
$$

- Tekanan tanah aktif akibat beban merata $\left(\mathrm{Pa}_{1}\right)$

$$
\begin{aligned}
\mathrm{Pa}_{1} & =\mathrm{Ka} \times \mathrm{q} \times \mathrm{H} \\
& =0,315 \times 5 \times 9 \\
& =14,175 \mathrm{kN} / \mathrm{m}
\end{aligned}
$$

- Tekanan tanah aktif akibat tanah di belakang dinding $\left(\mathrm{Pa}_{2}\right)$

$$
\begin{aligned}
\mathrm{Pa}_{2} & =1 / 2 \times \gamma_{\mathrm{b} 1} \times \mathrm{Ka} \times \mathrm{H}^{2} \\
& =1 / 2 \times 18,2 \times 0,315 \times 9^{2} \\
& =232,1865 \mathrm{kN} / \mathrm{m}
\end{aligned}
$$

b. Tekanan tanah pasif $(\mathrm{Pp})$

- Koefisien tekanan tanah pasif (Kp)

$$
\begin{aligned}
\mathrm{Kp} & =\operatorname{tg}^{2}\left(45+\frac{\Phi}{2}\right) \\
& =\operatorname{tg}^{2}\left(45+\frac{30,24}{2}\right) \\
& =\operatorname{tg}^{2}(60,675) \\
& =3,029
\end{aligned}
$$

- Tekanan tanah pasif akibat tanah (Pp)

$$
\begin{aligned}
\mathrm{Pp} & =1 / 2 \times \mathrm{Kp} \times \gamma \mathrm{b} \times \mathrm{D}^{2} \\
& =1 / 2 \times 3,029 \times 18,2 \times 7,9^{2} \\
& =1720,262 \mathrm{kN}
\end{aligned}
$$

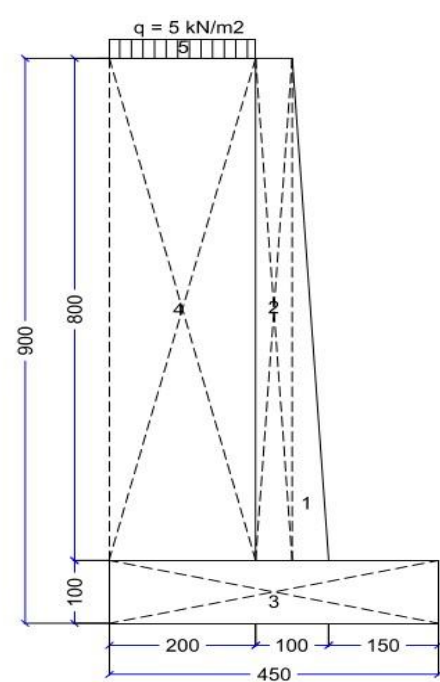

Gambar 5. Gaya vertikal dan momen yang bekerja pada DPT titk 1 
Tabel 3. Gaya vertikal dan momen yang bekerja pada DPT titik 1

\begin{tabular}{ccccc}
\hline Komponen & $\begin{array}{c}\text { Luas } \\
\left(\mathrm{m}^{2}\right)\end{array}$ & $\begin{array}{c}\mathrm{W} \\
(\mathrm{kN})\end{array}$ & $\begin{array}{c}\text { Jarak } \\
\text { dari } \\
\text { titik } \mathrm{O} \\
(\mathrm{m})\end{array}$ & $\begin{array}{c}\text { Momen } \\
(\mathrm{kNm})\end{array}$ \\
\hline 1 & 2 & 3 & 4 & 5 \\
\hline $\mathrm{W} 1$ & 2 & 48 & 1.83 & 88 \\
\hline $\mathrm{W} 2$ & 4 & 96 & 2.25 & 216 \\
\hline $\mathrm{W} 3$ & 4.5 & 108 & 2.25 & 243 \\
\hline $\mathrm{W} 4$ & 16 & 291.2 & 3.5 & 1019.2 \\
\hline $\mathrm{W} 5$ & 2 & 10 & 3.5 & 35 \\
\hline & $\Sigma \mathrm{V}=553.2$ & \multicolumn{2}{c}{$\Sigma \mathrm{Mr}=1601.2$} \\
\hline
\end{tabular}

\section{Cek Stabilitas}

a. Stabilitas terhadap guling

$\mathrm{Fgl}=\frac{\Sigma M R}{\Sigma M o}>2$

Momen pengguling $(\mathrm{mo}) \mathrm{Mo}=\left(\mathrm{Pa}_{1} \cdot \mathrm{H} / 2\right)+$ $\left(\mathrm{Pa}_{2} . \mathrm{H} / 3\right)$

$$
\begin{aligned}
& =(14,175 \times 9 / 2)+(232,186 \times 9 / 3) \\
& =63,787+696,558 \\
& =760,345 \mathrm{kNm} \\
& \text { Maka, } \\
& \text { Fgl }=\frac{1601,2}{760,345} \\
& =2,10>2 \quad \text { (OK) }
\end{aligned}
$$

b. Stabilitas terhadap geser

$$
\begin{aligned}
\text { Fgs } & =\frac{\Sigma R h}{\Sigma P h}>1,5 \\
\text { Rh } & =\Sigma \mathrm{V} \cdot \tan \phi_{2}+\text { B.c } c_{2}+\mathrm{Pp} \\
& =553,2 \times \tan 30,24+4,5 \times 19,4+1720,262 \\
& =2130
\end{aligned}
$$

Karena permukaan tanah adalah datar $(a=0)$, maka

$\mathrm{Ph}=\mathrm{Pa}$. Maka,

$$
\begin{aligned}
\text { Fgs } & =\frac{\Sigma V \cdot \tan \phi 2+\text { B.c2 }+P p}{P a 1+P a 2} \\
& =\frac{553,2 \times \tan 30,24+4,5 \times 19,4+1720,262}{14,175+232,186} \\
& =\frac{2130}{246,361}=8,6>1,5(\text { OK) }
\end{aligned}
$$

c. Stabilitas terhadap daya dukung tanah

$$
\begin{aligned}
\mathrm{X}_{\mathrm{e}} & =\frac{\Sigma M R-\Sigma M o}{\Sigma V} \\
& =\frac{1601,2-760,345}{553,2} \\
& =1,519 \\
\mathrm{e} & =\frac{B}{2}-\mathrm{x}_{e} \\
& =\frac{4,5}{2}-1,519 \\
& =0,731<\frac{B}{6}=\frac{4}{6}=0,75 \\
\mathrm{q}_{\text {toc }} & =\mathrm{q}_{\max }=\frac{\Sigma \mathrm{V}}{\mathrm{B}}\left(1+\frac{6 \mathrm{e}}{\mathrm{B}}\right) \\
& =\frac{553,2}{4,5}\left(1+\frac{6 \times 0,731}{4,5}\right) \\
& =242,752 \mathrm{kN} / \mathrm{m}^{2} \\
\mathrm{q}_{\text {heel }} & =\mathrm{q}_{\min }=\frac{\sum \mathrm{V}}{\mathrm{B}}\left(1-\frac{6 \mathrm{e}}{\mathrm{B}}\right) \\
& =\frac{553,2}{4,5}\left(1-\frac{6 \times 0,731}{4,5}\right) \\
& =3,114 \mathrm{kN} / \mathrm{m}^{2}
\end{aligned}
$$

B' $=\mathrm{B}-2 \mathrm{e}$

$=4,5-2 \times 0,731$

$$
=3,038 \mathrm{~m}
$$

$$
\mathrm{A}^{\prime}=\mathrm{B}^{\prime} \mathrm{x} 1
$$$$
=3,038 \mathrm{~m}
$$$$
\text { e } \quad=2,72
$$$$
\mathrm{N}_{\mathrm{q}}=\mathrm{e}^{(\pi \operatorname{tg} \phi)} \operatorname{tg}^{2}\left(45^{\circ}+\phi / 2\right)
$$$$
=2,72^{(3,14 \operatorname{tg} 30,24)}+\operatorname{tg}^{2}\left(45^{\circ}+30,24 / 2\right)
$$$$
=18,914
$$

$\mathrm{N}_{\mathrm{c}} \quad=(\mathrm{Nq}-1) \cdot \operatorname{ctg} \phi$

$=(18,914-1) \operatorname{ctg} 30,24$

$=30,729$

$\mathrm{N}_{\gamma} \quad=(\mathrm{Nq}-1) \tan (1,4 \phi)$

$=(18,914-1) \tan (1,4 \times 30,24)$

$=16,321$

$\mathrm{q}=\gamma_{2} \times \mathrm{D}$

$=18,2 \times 7,9$

$=143,78 \mathrm{kN} / \mathrm{m}^{2}$

$\mathrm{F}_{\mathrm{cd}} \quad=1+0,4 \frac{\mathrm{D}}{\mathrm{B}^{\prime}}$

$=1+0,4 \frac{7,9}{3,038}=2,040$

$\mathrm{F}_{\mathrm{qd}} \quad=1+2 \tan \phi_{2}\left(1-\sin \phi_{2}\right)^{2} \frac{\mathrm{D}}{\mathrm{B}^{\prime}}$

$=1+2 \tan 30,24(1-\sin 30,24)^{2} \frac{7,9}{3,038}$

$\begin{aligned} & =1,747 \\ \mathrm{~F}_{\mathrm{rd}} & =1\end{aligned}$ 
Sehingga :

$$
\begin{aligned}
\Psi^{\circ} & =\tan ^{-1}\left(\frac{\mathrm{Pa}}{\sum \mathrm{V}}\right) \\
& =\tan ^{-1}\left(\frac{246,361}{553,2}\right) \\
& =24^{\circ} \\
\mathrm{F}_{\mathrm{ci}}=\mathrm{F}_{\mathrm{qi}} \quad & =\left(1-\frac{\Psi^{\circ}}{90^{\circ}}\right)^{2} \\
& =\left(1-\frac{24}{90}\right)^{2} \\
& =0,537 \\
\mathrm{~F} \gamma \mathrm{i} & =\left(1-\frac{\Psi^{\circ}}{\phi^{\circ}}\right)^{2} \\
& =\left(1-\frac{24^{\circ}}{30,24^{\circ}}\right)^{2} \\
& =0,042
\end{aligned}
$$

$$
\begin{aligned}
\mathrm{q}_{\mathrm{u}}= & \mathrm{c}_{2} \cdot \mathrm{N}_{\mathrm{c}} \cdot \mathrm{F}_{\mathrm{cd}} \cdot \mathrm{F}_{\mathrm{ci}}+\mathrm{q} \cdot \mathrm{N}_{\mathrm{q}} \cdot \mathrm{F}_{\mathrm{qd}} \cdot \mathrm{F}_{\mathrm{qi}}+\frac{1}{2} \gamma_{2} \cdot \mathrm{B}^{\prime} \cdot \mathrm{N}_{\gamma} . \\
& \mathrm{F}_{\gamma \mathrm{d}} \cdot \mathrm{F}_{\gamma \mathrm{r}} \\
= & (19,4)(30,279)(2,040)(0,537)+(143,78) \\
& (18,914)(1,747)(0,537)+\frac{1}{2}(18,2)(3,038) \\
& (16,321)(1)(0,042) \\
= & 643,498+2454,109+18,950 \\
= & 3116,557 \mathrm{kN} / \mathrm{m}^{2}
\end{aligned}
$$

Maka, faktor keamanan terhadap daya dukung tanah adalah :

Fs(daya dukung)

$$
\begin{aligned}
& =\frac{\mathrm{qu}}{\mathrm{qmax}} \\
& =\frac{3116,557}{242752} \\
& =12,838>3
\end{aligned}
$$

(OK)

\section{2) DPT titik 2}

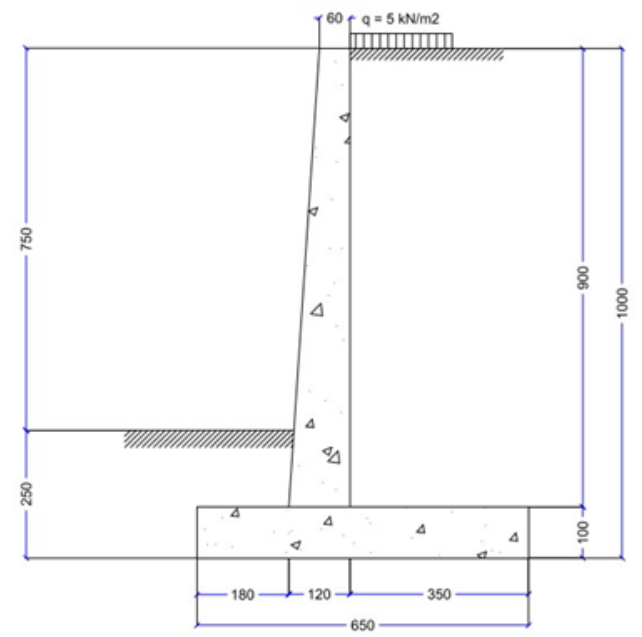

Gambar 6. Diagram tekanan tanah DPT titik 2

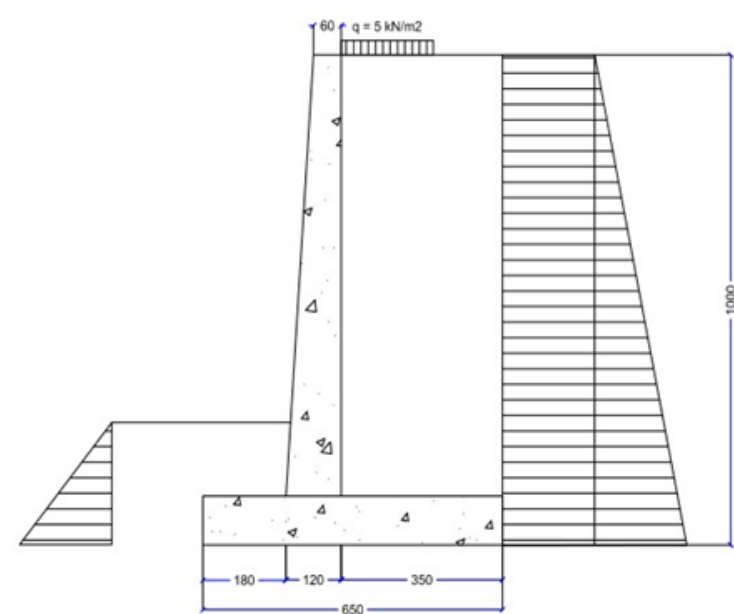

Gambar 7. Diagram tekanan tanah DPT titik 2

a. Tekanan tanah aktif (Pa)

- Koefisien tekanan tanah aktif $(\mathrm{Ka})$

$$
\begin{aligned}
\mathrm{Ka} & =\operatorname{tg}^{2}\left(45-\frac{\phi}{2}\right) \\
& =\operatorname{tg}^{2}\left(45-\frac{31,35}{2}\right) \\
& =\operatorname{tg}^{2}(29,325) \\
& =0,315
\end{aligned}
$$

- Tekanan tanah aktif akibat beban merata $\left(\mathrm{Pa}_{1}\right)$

$$
\begin{aligned}
\mathrm{Pa}_{1} & =\mathrm{Ka} \times \mathrm{q} \times \mathrm{H} \\
& =0,315 \times 5 \times 10 \\
& =15,75 \mathrm{kN} / \mathrm{m}
\end{aligned}
$$

- Tekanan tanah aktif akibat tanah di belakang dinding $\left(\mathrm{Pa}_{2}\right)$

$$
\begin{aligned}
\mathrm{Pa}_{2} & =1 / 2 \times \gamma_{\mathrm{b} 1} \times \mathrm{Ka}^{2} \mathrm{H}^{2} \\
& =1 / 2 \times 18,2 \times 0,315 \times 10^{2} \\
& =286,65 \mathrm{kN} / \mathrm{m}
\end{aligned}
$$

b. Tekanan tanah pasif $(\mathrm{Pp})$

- Koefisien tekanan tanah aktif (Ka)

$$
\begin{aligned}
\mathrm{Ka} & =\operatorname{tg}^{2}\left(45-\frac{\phi}{2}\right) \\
& =\operatorname{tg}^{2}\left(45-\frac{31,35}{2}\right) \\
& =\operatorname{tg}^{2}(29,325) \\
& =0,315
\end{aligned}
$$

- Tekanan tanah aktif akibat beban merata $\left(\mathrm{Pa}_{1}\right)$

$\mathrm{Pa}_{1}=\mathrm{Ka} \times \mathrm{q} \times \mathrm{H}$

$$
=0,315 \times 5 \times 10
$$$$
=15,75 \mathrm{kN} / \mathrm{m}
$$

- Tekanan tanah aktif akibat tanah di belakang dinding $\left(\mathrm{Pa}_{2}\right)$

$$
\begin{aligned}
\mathrm{Pa}_{2} & =1 / 2 \times \gamma_{\mathrm{b} 1} \times \mathrm{Ka} \times \mathrm{H}^{2} \\
& =1 / 2 \times 18,2 \times 0,315 \times 10^{2} \\
& =286,65 \mathrm{kN} / \mathrm{m}
\end{aligned}
$$




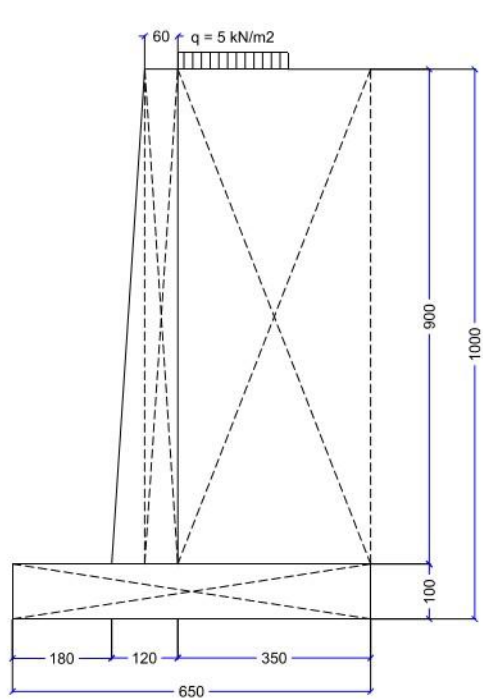

Gambar 7. Gaya vertikal dan momen yang bekerja pada DPT titik 2

Tabel 4. Gaya vertikal dan momen yang bekerja pada DPT titik 2

\begin{tabular}{|c|c|c|c|c|}
\hline Komponen & $\begin{array}{c}\text { Luas } \\
\left(\mathrm{m}^{2}\right)\end{array}$ & $\begin{array}{c}\mathrm{W} \\
(\mathrm{kN})\end{array}$ & $\begin{array}{c}\text { Jarak } \\
\text { dari titik } \\
\mathrm{O}(\mathrm{m}) \\
\end{array}$ & $\begin{array}{c}\text { Momen } \\
(\mathrm{kNm})\end{array}$ \\
\hline 1 & 2 & 3 & 2 & 5 \\
\hline W1 & 2.7 & 64.8 & 2.2 & 142.56 \\
\hline W2 & 5.4 & 129.6 & 2.7 & 349.22 \\
\hline W3 & 6.5 & 156 & 3.25 & 507 \\
\hline W4 & 31.5 & 573.3 & 4.75 & 2723.175 \\
\hline \multirow[t]{2}{*}{ W5 } & 3.5 & 17.5 & 4.75 & 83.125 \\
\hline & \multicolumn{2}{|c|}{$\Sigma \mathrm{V}=941.2$} & \multicolumn{2}{|c|}{$\Sigma \mathrm{Mr}=3805.78$} \\
\hline
\end{tabular}

\section{Cek Stabilitas}

a. Stabilitas terhadap guling

$$
\mathrm{Fgl}=\frac{\Sigma M R}{\Sigma M o}>2
$$

b. Momen pengguling (mo)

$$
\begin{aligned}
\text { Mo } & =\left(\mathrm{Pa}_{1} . \mathrm{H} / 2\right)+\left(\mathrm{Pa}_{2} . \mathrm{H} / 3\right) \\
& =(15,75 \times 10 / 2)+(286,65 \times 10 / 3) \\
& =78,75+1433,25 \\
& =1512 \mathrm{kNm} \\
\text { Maka, Fgl } & =\frac{3805,78}{1512} \\
& =2,51>2 \quad \text { (OK) }
\end{aligned}
$$

\section{(OK)}

c. Stabilitas terhadap geser

$$
\begin{aligned}
\mathrm{Fgs} & =\frac{\Sigma R h}{\Sigma P h}>1,5 \\
\mathrm{Rh} & =\sum \mathrm{V} \cdot \tan \phi_{2}+\mathrm{B} \cdot \mathrm{c}_{2}+\mathrm{Pp} \\
= & 941,2 \times \tan 30,24+6,5 \times 19,4 \\
& +172,274 \\
= & 847,045
\end{aligned}
$$

$$
=\frac{941,2 \times \tan 30,24+6 \times 19,4+172,274}{15,75+28665}
$$

Karena permukaan tanah adalah datar $(a=0)$, maka

$\mathrm{Ph}=\mathrm{Pa}$. Maka, Fgs $\quad=\frac{\Sigma \text { V.tan } \phi 2+\mathrm{B} \cdot \mathrm{c} 2+\mathrm{Pp}}{P a 1+P a 2}$

$$
=\frac{837,345}{302,4}=2,76>1,5 \text { (OK) }
$$

c. Stabilitas terhadap daya dukung tanah

$$
\begin{aligned}
& \begin{aligned}
\mathrm{X}_{\mathrm{e}} & =\frac{\Sigma M R-\Sigma M 0^{*}}{\Sigma V} \\
& =\frac{3805,78-1512}{941,2}
\end{aligned} \\
& =2,437 \\
& \text { e } \quad=\frac{B}{2}-\mathrm{x}_{\mathrm{e}} \\
& =\frac{6,5}{2}-2,437 \\
& =0,813<\frac{B}{6}=\frac{6,5}{6}=1,083 \\
& \mathrm{q}_{\text {toc }}=\mathrm{q}_{\max }=\frac{\Sigma \mathrm{V}}{\mathrm{B}}\left(1+\frac{6 \mathrm{e}}{\mathrm{B}}\right) \\
& =\frac{941,2}{6,5}\left(1+\frac{6 \times 0,813}{6,5}\right) \\
& =253,466 \mathrm{kN} / \mathrm{m}^{2} \\
& \mathrm{q}_{\text {heel }}=\mathrm{q}_{\min }=\frac{\Sigma \mathrm{V}}{\mathrm{B}}\left(1-\frac{6 \mathrm{e}}{\mathrm{B}}\right) \\
& =\frac{941,2}{6,5}\left(1-\frac{6 \times 0,813}{6,5}\right) \\
& =36,133 \mathrm{kN} / \mathrm{m}^{2} \\
& \text { B' }=\mathrm{B}-2 \mathrm{e} \\
& =6,5-2 \times 0,813 \\
& =4,874 \mathrm{~m} \\
& \mathrm{~A}^{\prime} \quad=\mathrm{B}^{\prime} \times 1 \\
& =4,874 \mathrm{~m} \\
& \begin{array}{ll}
\mathrm{e} & =2,72 \\
\mathrm{~N}_{\mathrm{q}} & =\mathrm{e}^{(\pi \mathrm{t} \phi)} \operatorname{tg}^{2}\left(45^{\circ}+\phi / 2\right)
\end{array} \\
& =2,72^{(3,14 \text { 때 } 30,24)}+\operatorname{tg}^{2}\left(45^{\circ}+30,24 / 2\right) \\
& =18,914 \\
& \mathrm{~N}_{\mathrm{c}} \quad=(\mathrm{Nq}-1) \cdot \operatorname{ctg} \phi \\
& =(18,914-1) \operatorname{ctg} 30,24 \\
& =30,729 \\
& \mathrm{~N}_{\gamma} \quad=(\mathrm{Nq}-1) \tan (1,4 \phi) \\
& =(18,914-1) \tan (1,4 \times 30,24) \\
& =16,321 \\
& \mathrm{q}=\gamma_{2} \times \mathrm{D} \\
& =18,2 \times 2,5 \\
& =45,5 \mathrm{kN} / \mathrm{m}^{2} \\
& \mathrm{~F}_{\mathrm{cd}}=1+0,4 \frac{\mathrm{D}}{\mathrm{B}^{\prime}} \\
& =1+0,4 \frac{2,5}{4,874}=1,205
\end{aligned}
$$




$$
\begin{aligned}
\mathrm{F}_{\mathrm{qd}} & =1+2 \tan \phi_{2}\left(1-\sin \phi_{2}\right)^{2} \frac{\mathrm{D}}{\mathrm{B}^{\prime}} \\
& =1+2 \tan 30,24(1-\sin 30,24)^{2} \frac{2,5}{4,874} \\
& =1,147 \\
\mathrm{~F}_{\text {rd }} & =1 \\
\Psi^{\circ} \quad & \tan ^{-1}\left(\frac{\mathrm{Pa}}{\Sigma V}\right) \\
& =\tan ^{-1}\left(\frac{302,4}{941,2}\right) \\
& =17,7^{\circ} \\
\mathrm{F}_{\mathrm{ci}} \quad & \mathrm{F}_{\mathrm{qi}} \quad=\left(1-\frac{\Psi^{\circ}}{90^{\circ}}\right)^{2} \\
& =\left(1-\frac{17,7}{90}\right)^{2} \\
& =0,645^{\circ} \\
\mathrm{F} \gamma \mathrm{i} \quad & \left(1-\frac{\Psi^{\circ}}{\phi^{\circ}}\right)^{2} \\
& =\left(1-\frac{17,7^{\circ}}{30,24^{\circ}}\right)^{2} \\
& =0,171
\end{aligned}
$$

Sehingga :

$q u=c 2 . N c . F c d . F c i+q \cdot N q . F q d . F q i$

$$
\begin{aligned}
+ & \frac{1}{2} \gamma . \mathrm{B} \cdot \mathrm{N}_{\gamma} . \mathrm{F}_{\gamma \mathrm{d}} . \mathrm{F}_{\gamma \mathrm{i}} \\
= & (19,4)(30,279)(1,205)(0,645) \\
& (45,5)(18,914)(1,147)(0,645)+ \\
& \frac{1}{2}(18,2)(4,874)(16,321)(1)(0,171) \\
= & 456,551+636,675+123,785 \\
= & 1217,011 \mathrm{kN} / \mathrm{m}^{2}
\end{aligned}
$$

Maka, faktor keamanan terhadap daya dukung tanah adalah :

$$
\begin{aligned}
\text { Fs(daya dukung) } & =\frac{\mathrm{qu}}{\mathrm{qmax}} \\
& =\frac{1217,011}{253,466} \\
& =4,80>3 \quad \text { (OK) }
\end{aligned}
$$

\section{KESIMPULAN}

Dari hasil analisis penulisan ini dapat diambil kesimpulan seperti berikut ini:

1. Dari hasil perencanaan, dimensi dinding penahan tanah yang digunakan untuk titik 1 didapat nilai stabilitas guling 2.10, stabilitas geser 8,6 dan daya dukung tanah 12,838. Sedangkan dimensi dinding penahan tanah yang digunakan untuk titik 2 didapat nilai stabilitas guling 2.51, stabilitas geser 2.80 dan daya dukung tanah 4.8 .

2. Dari hasil perhitungan yang sudah dilakukan, desain dinding penahan tanah untuk titik BH1 dan $\mathrm{BH} 2$ sudah aman terhadap stabilitas guling, geser dan daya dukung tanah.

\section{DAFTAR PUSTAKA}

Agar, Vendelinus, Suhudi Suhudi, and Andy Kristafi Arifianto. "Studi Efisiensi Lebar Alas Dinding Penahan Tanah Tipe Kantilever pada Jalan Brigjend Abdul Manan Wijaya Kecamatan Pujon Kabupaten Malang." Reka Buana: Jurnal Ilmiah Teknik Sipil dan Teknik Kimia 5.1 (2020): 90-97.

Andila, Ayu. Perencanaan Dinding Penahan Tanah Dan Perencanaan Perkerasan Jalan Pada Ruas Jalan Km 7 Batas Kota Tanah Grogot-Lolo Kuaro Sta. 0+ 420-Sta. O+ 500, Kab. Paser, Kalimantan Timur. Diss. University of Muhammadiyah Malang, 2017.

Badan Standarisasi Nasional. 2013. Persyaratan Beton Struktural Untuk Bangunan Gedung. SNI No.2847:2013. Badan Standarisasi Nasional. Jakarta

Badan Standarisasi Nasional. 2017. Persyaratan Perancangan Geoteknik. SNI No.8460: 2017. Badan Standarisasi Nasional. Jakarta

Hardiyatmo, Hary Christady. Penanganan tanah longsor dan erosi. Indonesia, Gadjah Mada University Press, 2006.

Nugraha, Arya. Perencanaan Dinding Penahan Tanah Dengan Menggunakan Program GEO 5. Diss. Universitas Muhammadiyah Surakarta, 2013.

Saputra, Septian Adi. "Analisis Stabilitas Lereng Dengan Perkuatan Dinding Penahan Tanah Kantilever Dan Geotekstil Pada Ruas Jalan Lintas Liwa-Simpang Gunung Kemala Km. 268+ 550." (2017).

Wagola, Erwin Syaiful, and Mentari Rasyid. "Analisis Stabilitas Dinding Penahan Tanah Tipe Kantilever pada Landfill TPA Kota Masohi Kabupaten Maluku Tengah Provinsi Maluku." Rekayasa Sipil 14.1 (2020): 70-74. 